\title{
Physiological relation between respiration activity and heterologous expression of selected benzoylformate decarboxylase variants in Escherichia coli
}

Thomas G Palmen ${ }^{1 \dagger}$, Jens Nieveler ${ }^{1 \dagger}$, Bettina Frölich ${ }^{2}$, Wiltrud Treffenfeldt ${ }^{3}$, Martina Pohl ${ }^{2,4}$, Jochen Büchs ${ }^{1 *}$

\begin{abstract}
Background: The benzoylformate decarboxylase (BFD) from Pseudomonas putida is a biotechnologically interesting biocatalyst. It catalyses the formation of chiral 2-hydroxy ketones, which are important building blocks for stereoselective syntheses. To optimise the enzyme function often the amino acid composition is modified to improve the performance of the enzyme. So far it was assumed that a relatively small modification of the amino acid composition of a protein does not significantly influence the level of expression or media requirements. To determine, which effects these modifications might have on cultivation and product formation, six different BFDvariants with one or two altered amino acids and the wild type BFD were expressed in Escherichia coli SG13009 pKK233-2. The oxygen transfer rate (OTR) as parameter for growth and metabolic activity of the different E. coli clones was monitored on-line in LB, TB and modified PanG mineral medium with the Respiratory Activity MOnitoring System (RAMOS).

Results: Although the E. coli clones were genetically nearly identical, the kinetics of their metabolic activity surprisingly differed in the standard media applied. Three different types of OTR curves could be distinguished. Whereas the first type (clones expressing Leu476Pro-Ser181Thr or Leu476Pro) had typical OTR curves, the second type (clones expressing the wild type BFD, Ser181Thr or His281Ala) showed an early drop of OTR in LB and TB medium and a drastically reduced maximum OTR in modified PanG mineral medium. The third type (clone expressing Leu476GIn) behaved variable. Depending on the cultivation conditions, its OTR curve was similar to the first or the second type. It was shown, that the kinetics of the metabolic activity of the first type depended on the concentration of thiamine, which is a cofactor of BFD, in the medium. It was demonstrated that the cofactor binding strength of the different BFD-variants correlated with the differences in metabolic activity of their respective host strain.

Conclusions: The BFD-variants with high cofactor binding affinity (wild type, His281Ala, Ser181Thr) obviously extract thiamine from the medium and bind it tightly to the enzyme. This might explain the hampered growth of these clones. In contrast, growth of clones expressing variants with low cofactor binding affinity (Leu476His, Leu476Pro, Leu476Pro-Ser181Thr) is not impaired. Leu476GIn has an intermediate cofactor binding strength, thus, growth of its host strain depends on the specific cultivation conditions. This paper shows that slight differences of the amino acid composition can affect protein expression and cultivation and might require an adaptation of media components. Effects such as the observed are hardly foreseeable and difficult to detect in conventional screening processes. Via small scale experiments with on-line measurements in shake flasks such effects influencing the cultivation and product formation can be detected and avoided.
\end{abstract}

\footnotetext{
*Correspondence: jochen.buechs@avt.rwth-aachen.de

+ Contributed equally

'AVT - Aachener Verfahrenstechnik, Biochemical Engineering, RWTH Aachen

University, Worringerweg 1, D-52074 Aachen, Germany

Full list of author information is available at the end of the article
} 


\section{Background}

Biocatalysts, i. e. whole cell systems or enzymes have found increased use in industrial biotechnology. To further increase the number of industrial biotechnological processes, new biocatalysts are needed. By utilizing the existing biodiversity [1], enzymes from microorganisms found in nature are screened to find suitable biocatalysts for such processes. Besides these naturally occurring sources of potential enzymes, techniques such as directed evolution [2] are applied. With this technique, mutations in selected genes can be generated. If applied to enzymes, single or few amino acids in these enzymes can be exchanged, resulting in different enzyme variants. In this way, clone libraries of microorganisms harbouring the genes for different variants are created which are screened for desired attributes, e. g. improved enzyme activity, thermostability or stereoselectivity.

One enzyme with an already high stereoselectivity [3] is the benzoylformate decarboxylase from Pseudomonas putida. It is named BFDC in recent publications. In this work, we stick to the older abbreviation BFD to be consistent with our previous publications [4-6]. While its main reaction, the non-oxidative decarboxylation of benzoylformate is part of the mandelate biosynthetic pathway [7-9], the physiological function of the biotechnologically interesting side reaction, the carboligation [10] is unknown. In this side reaction, BFD catalyses the formation of chiral 2-hydroxy ketones from benzaldehyde or benzaldehyde derivates as acyl donors and acetaldehyde as the acyl acceptor [11]. 2-Hydroxy ketones are important structural subunits in many biologically active natural products and are also important building blocks for stereoselective syntheses [3], e. g. for the synthesis of ephedrine or bupropion [12]. Depending on the acyl donor, the enantiomeric excess of the product synthesised by BFD catalysis varies as well as the amount of converted substrate in a given time $[3,11]$. To improve the carboligase activity of BFD, a combination of directed evolution and site-directed mutagenesis has been applied [4]. Upon induction of protein expression, these respective recombinant $E$. coli clones expressed different BFD-variants. Other attempts aimed to alter the substrate specificity of BFD $[5,13]$ and to improve the stereoselectivity of BFD for different substrates [14].

Kensy et al. [15] showed that the induction of cultures can affect the growth of the applied microorganisms. Therefore, expressing different BFD-variants might result in different kinetics of the metabolic activity of the applied strains. Hence, in screening processes, the growth of the cultures has to be monitored. Without appropriate measurement systems, endpoint measurements or costly sampling during cultivation have to be conducted in screening processes. Evaluation of the cultivation performance and product formation on the basis of these few data is problematic. In this study, the RAMOS (Respiratory Activity MOnitoring System) was applied to measure the oxygen transfer rate (OTR) on-line as a parameter for the growth and metabolism of the investigated organisms. In this work, the thiamine auxotroph strain $E$. coli SG13009 pKK233-2 was applied to express different BFD-variants. Thiamine auxotroph strains, such as E. coli DH5 $\alpha$, E. coli JM109 or E. coli M15 are routinely utilized in laboratories all over the world. They are also used to express thiamine dependent enzymes [16-19].

The aim of this study is to show the physiological relation between the respiration activity and the heterologous expression of selected BFD-variants under different culture conditions. This example should increase the awareness for effects that can occur during cultivation and that may influence the expression of the product and the cultivation itself.

\section{Methods}

\section{Microorganism}

Different recombinant clones of the thiamine auxotroph strain E. coli SG13009 (Qiagen, Hilden, Germany) were used for the experiments, containing the plasmid pKK233-2 (Pharmacia, Uppsala, Sweden) with the genes encoding different benzoylformate decarboxylase (BFD) variants, including the information for a $\mathrm{C}$-terminal $\mathrm{His}_{6}$-tag. The applied expression system has a tightly regulated expression of the BFD variants to prevent unwanted expression without the addition of the inducer IPTG. The wild type-BFD originates from Pseudomonas putida [4]. Upon induction with IPTG, the clones produce the wild type BFD or BFD variants that differ in one or two amino acids. Table 1 shows the applied clones and the used abbreviations. The genotype of the applied strain E. coli SG13009 is $\mathrm{Nal}^{\mathrm{S}}, \mathrm{Str}^{\mathrm{S}}, \mathrm{Rif}^{\mathrm{S}}$, $\mathrm{Thi}^{-}, \mathrm{Lac}^{-}, \mathrm{Ara}^{+}, \mathrm{Gal}^{+}, \mathrm{Mtl}^{-}, \mathrm{F}^{-}, \mathrm{RecA}^{+}, \mathrm{Uvr}^{+}, \mathrm{Lon}^{+}$.

To prepare stock cultures, precultures of E. coli SG13009 pKK233-2 clones in LB medium were made. After reaching an optical density (OD) of 3, glycerol solution was added as a cryoprotective, resulting in a final glycerol concentration of $300 \mathrm{~g} / \mathrm{L}$. The cultures were stored at $-20^{\circ} \mathrm{C}$ in $1 \mathrm{~mL}$ aliquots in cryo-vials.

\section{Media}

E. coli SG13009 pKK233-2 was cultivated in buffered LB medium with $10 \mathrm{~g} / \mathrm{L}$ glycerol. It consists of $5 \mathrm{~g} / \mathrm{L}$ yeast extract, $10 \mathrm{~g} / \mathrm{L}$ tryptone, $12.54 \mathrm{~g} / \mathrm{L} \mathrm{K}_{2} \mathrm{HPO}_{4}$ and $2.31 \mathrm{~g} /$ $\mathrm{L} \mathrm{KH}_{2} \mathrm{PO}_{4}$. Another complex medium, TB medium, was also applied for the cultivations. It consists of $24 \mathrm{~g} / \mathrm{L}$ yeast extract, $12 \mathrm{~g} / \mathrm{L}$ tryptone, $12.54 \mathrm{~g} / \mathrm{L} \mathrm{K}_{2} \mathrm{HPO}_{4}, 2.31$ 
Table 1 Applied clones and abbreviations

\begin{tabular}{ll}
\hline clone & abbreviation \\
\hline Escherichia coli SG13009:pKK233-2-BFD-wt-His & wt \\
\hline Escherichia coli SG13009:pKK233-2-BFD-His281Ala-His & His281Ala \\
\hline Escherichia coli SG13009:pKK233-2-BFD-Leu476GIn-His & Leu476Gln \\
\hline Escherichia coli SG13009:pKK233-2-BFD-Leu476His-His & Leu476His \\
\hline Escherichia coli SG13009:pKK233-2-BFD-Leu476Pro-His & Leu476Pro \\
\hline Escherichia coli SG13009:pKK233-2-BFD-Leu476Pro-Ser181Thr-His & Leu476Pro-Ser181Thr \\
\hline Escherichia coli SG13009:pKK233-2-BFD-Ser181Thr-His & Ser181Thr \\
\hline
\end{tabular}

$\mathrm{g} / \mathrm{L} \mathrm{KH}_{2} \mathrm{PO}_{4}$ and $5 \mathrm{~g} / \mathrm{L}$ glycerol. Furthermore, modified PanG mineral medium [20] was used for the cultivations. It consists of $1.6 \mathrm{~g} / \mathrm{L} \mathrm{NaH}{ }_{2} \mathrm{PO}_{4}{ }^{*} \mathrm{H}_{2} \mathrm{O}, 3.2 \mathrm{~g} / \mathrm{L}$ $\mathrm{KH}_{2} \mathrm{PO}_{4}, 2.6 \mathrm{~g} / \mathrm{L} \mathrm{K}_{2} \mathrm{HPO}_{4}, 0.2 \mathrm{~g} / \mathrm{L} \mathrm{NH} \mathrm{NH}_{4} \mathrm{Cl}, 2.0 \mathrm{~g} / \mathrm{L}$ $\left(\mathrm{NH}_{4}\right)_{2} \mathrm{SO}_{4}, 0.6 \mathrm{~g} / \mathrm{L} \mathrm{MgSO}_{4}, 0.2 \mathrm{~g} / \mathrm{L} \mathrm{CaCl}_{2}{ }^{*} \mathrm{H}_{2} \mathrm{O}, 5 \mathrm{~g} / \mathrm{L}$ glycerol and $1 \mathrm{~mL} / \mathrm{L}$ trace element solution. The trace element solution consists of $5 \mathrm{~mL} / \mathrm{L} \mathrm{H}_{2} \mathrm{SO}_{4}$ (conc.), $6 \mathrm{~g} /$ $\mathrm{L} \mathrm{CuSO}_{4}{ }^{*} 5 \mathrm{H}_{2} \mathrm{O}, 0.08 \mathrm{~g} / \mathrm{L} \mathrm{KI}, 3 \mathrm{~g} / \mathrm{L} \mathrm{MnSO}_{4}{ }^{*} \mathrm{H}_{2} \mathrm{O}, 0.3 \mathrm{~g} /$ $\mathrm{L} \mathrm{Na}_{2} \mathrm{MoO}_{4}, 0.02 \mathrm{~g} / \mathrm{L} \mathrm{H}_{3} \mathrm{BO}_{3}, 0.5 \mathrm{~g} / \mathrm{L} \mathrm{CoCl} \mathrm{CoC}_{2}, 20 \mathrm{~g} / \mathrm{L}$ $\mathrm{ZnCl}_{2}$ and $65 \mathrm{~g} / \mathrm{L} \mathrm{FeSO}_{4}{ }^{*} 7 \mathrm{H}_{2} \mathrm{O}$. The $\mathrm{pH}$ of all media was adjusted to 7.0. Furthermore, $0.1 \mathrm{~g} / \mathrm{L}$ ampicillin was added to each medium. As the applied strain has a neomycin/kanamycin selection marker, additionally $0.05 \mathrm{~g} / \mathrm{L}$ neomycin was added to each medium. Although $E$. coli SG13009 pKK233-2 is a thiamine auxotroph strain, no additional thiamine was added to the complex LB and TB medium, according to the literature [21-23]. For the cultivations with additional thiamine, sterile filtrated thiamine hydrochloride stock solution ( $1 \mathrm{~g} / \mathrm{L})$ was added. Final thiamine concentrations were $0.002 \mathrm{mg} / \mathrm{L}$, $0.02 \mathrm{mg} / \mathrm{L}, 0.1 \mathrm{mg} / \mathrm{L}, 0.2 \mathrm{mg} / \mathrm{L}, 2 \mathrm{mg} / \mathrm{L}, 10 \mathrm{mg} / \mathrm{L}$ and 20 $\mathrm{mg} / \mathrm{L}$.

\section{Cultivations}

For all cultivations, precultures were made. The precultures were inoculated with a stock culture of the given E. coli SG13009 pKK233-2 clone and cultivated in the same cultivation vessel under the same cultivation conditions as the given main culture. Main cultures were inoculated with an inoculation volume of $1 \%(\mathrm{v} / \mathrm{v})$ of the main culture volume.

To determine the BFD portion of total protein, the carboligation activity in crude extract and the optical density cultivations were conducted in $250 \mathrm{~mL}$ Erlenmeyer flasks filled with $25 \mathrm{~mL}$ buffered LB medium with $10 \mathrm{~g} / \mathrm{L}$ glycerol. The cultures were grown at $37^{\circ} \mathrm{C}$, a shaking diameter of $50 \mathrm{~mm}$ and a shaking frequency of $150 \mathrm{rpm}$.

The oxygen transfer rate (OTR) in shake flasks was measured online with a self made RAMOS (Respiratory Activity MOnitoring System) device, as described by Anderlei et al. [24]. The RAMOS cultivations were performed in modified $250 \mathrm{~mL}$ Erlenmeyer flasks (RAMOS flasks) as described by Anderlei and Büchs [25]. The applied RAMOS device allows to run up to 8 modified Erlenmeyer flasks in parallel. The cultures were grown in 10 or $25 \mathrm{~mL}$ medium (buffered LB medium with $10 \mathrm{~g} / \mathrm{L}$ glycerol, TB medium or modified PanG mineral medium) at $37^{\circ} \mathrm{C}$, a shaking diameter of $50 \mathrm{~mm}$ and a shaking frequency of 150,320 or $400 \mathrm{rpm}$. No antifoaming agents were added to the medium during the cultivations with high shaking frequencies.

BFD expression was induced by adding IPTG stock solution $(100 \mathrm{mM})$ resulting in a final IPTG concentration of $1 \mathrm{mM}$.

\section{Cell disruption}

Cell disruption was applied as described by Losen et al. [26]. After centrifuging $3 \mathrm{~mL}$ culture medium for 15 min at $600 \mathrm{~g}$, the cell pellets were frozen at $-20^{\circ} \mathrm{C}$ and subsequently resuspended in extraction buffer $(50 \mathrm{mM}$ $\mathrm{K}_{3} \mathrm{PO}_{4}, 5 \mathrm{mM} \mathrm{MgSO}, 0.5 \mathrm{mM}$ thiamine diphosphate (ThDP), pH 7). These samples were centrifuged for 10 min at $10000 \mathrm{~g}$ and the pellet was resuspended in extraction buffer with $1 \mathrm{mg} / \mathrm{mL}$ lysozyme. After incubation for $1.5 \mathrm{~h}$ at $30^{\circ} \mathrm{C}$ the samples were ultrasonicated for $5 \mathrm{~min}$ and centrifuged for $15 \mathrm{~min}$ at $10000 \mathrm{~g}$. The supernatants were used to determine the BFD portion of total protein, the protein determination and the volumetric carboligation activity in crude extract.

\section{BFD portion of total protein}

The portion of BFD in the cell extract was calculated by the quotient of the specific activity in the cell extract and the specific activity of purified BFD, as described by Losen et al. [26]. Determination of protein concentration was performed according to Bradford [27] using BSA for calibrations. Table 2 shows the specific decarboxylation activities that were applied.

\section{Volumetric carboligation activity in crude extract}

To determine the carboligation activity of the wild type BFD and the BFD-variants, cell extract was diluted 1/20 in reaction buffer ( $1.5 \mathrm{M}$ ethanol, $50 \mathrm{mM} \mathrm{K}_{3} \mathrm{PO}_{4}, 2.5$ 
Table 2 Specific decarboxylase activity of selected BFDvariants

\begin{tabular}{lc}
\hline BFD-variant & Specific decarboxylation activity [U/mg BFD] \\
\hline wt & 390 \\
\hline His281Ala & 35 \\
\hline Leu476Gln & 246 \\
\hline Leu476Pro & 63 \\
\hline Leu476Pro-Ser181Thr & 150 \\
\hline Ser181Thr & 236 \\
\hline
\end{tabular}

$\left.\mathrm{mM} \mathrm{MgSO}_{4}, 0.1 \mathrm{mM} \mathrm{ThDP}\right)$. An equal volume of substrate solution (1 M acetaldehyde, $80 \mathrm{mM}$ benzaldehyde) was added. After incubation for $30 \mathrm{~min}$ at $30^{\circ} \mathrm{C}$, the reaction was stopped by heating for $2 \mathrm{~min}$ at $95^{\circ} \mathrm{C}$. The amount of formed 2-hydroxy-1-phenyl-propanone (2HPP) was measured using a HPLC system. Separation was performed on a RP8-column (Macherey \& Nagel, Düren, Germany) using 0.5\%/20\% acetic acid/acetonitrile $(\mathrm{v} / \mathrm{v})$ as eluent. The flow rate was $1.1 \mathrm{~mL} / \mathrm{min}$.

\section{Cell density}

To determine the cell density, the optical density was measured with a spectrophotometer (Uvikon 922 A, Kontron Instruments, Milano, Italy) at a wavelength of $600 \mathrm{~nm} .10 \mathrm{~mm}$ cuvettes were applied. To keep the measurements in the linear range between 0.03 and 0.3 , the samples were diluted with $\mathrm{NaCl}$ solution $(9 \mathrm{~g} / \mathrm{L})$. Cuvettes containing only $\mathrm{NaCl}$ solution $(9 \mathrm{~g} / \mathrm{L})$ were used as blanks. Furthermore, the optical density of sterile medium was subtracted from the measured optical density.

\section{Purification of selected BFD-variants}

Purification of the wild type BFD and BFD-variants was performed as described for pyruvate decarboxylase [6] using potassium phosphate buffer $(50 \mathrm{mM}, \mathrm{pH}$ 7.0) for Ni-NTA chromatography and potassium phosphate buffer $(50 \mathrm{mM}, \mathrm{pH} 6.0)$ containing ThDP $(0.5 \mathrm{mM})$ and $\mathrm{MgSO}_{4}(2.5 \mathrm{mM})$ as elution buffer for the subsequent gel chromatography. Lyophilised BFD-variants were stored at $-20^{\circ} \mathrm{C}$.

\section{Enzymatic synthesis in buffer}

The initial carboligase activities were measured as described by Lingen et al. [4]. 10-50 $\mu$ g purified wild type BFD or BFD-variant were incubated in $0.5 \mathrm{~mL}$ of $50 \mathrm{mM} \mathrm{KPi}, \mathrm{pH}$ 7.0, containing $0.5 \mathrm{mM}$ ThDP, $2.5 \mathrm{mM}$ $\mathrm{MgSO}_{4}$ in the presence of 20,40 or $60 \mathrm{mM}$ benzaldehyde and $500 \mathrm{mM}$ acetaldehyde for $30 \mathrm{~min}$ at $30^{\circ} \mathrm{C}$. The enzymes were heat inactivated and the resulting 2-HPP formed was measured using an analytical HPLC system (Gynkotek, Germering, Germany) with an ultraviolet monitor $(263 \mathrm{~nm})$. Separation was performed on a 318-
Hypersil column ( $C \& S$, Langerwehe, Germany) using $0.5 \% / 20 \%$ acetic acid/acetonitrile $(\mathrm{v} / \mathrm{v})$ as eluent. The flow rate was $1.1 \mathrm{~mL} / \mathrm{min}$. The retention time of 2-HPP was $12.8 \mathrm{~min}$.

\section{Stability of cofactor binding}

The stability of cofactor binding was tested as described by Lingen et al. [4]. $0.1 \mathrm{mg} / \mathrm{mL}$ of the BFD-variants were incubated in potassium phosphate buffer without the cofactors ThDP and $\mathrm{MgSO}_{4}$ for $24 \mathrm{~h}$. Then, $50 \mu \mathrm{L}$ samples were removed and decarboxylase activity was determined. For this purpose, a coupled enzymatic test as described by Iding et al. was conducted [11]. An assay mixture was applied consisting of $100 \mu \mathrm{L}$ benzoylformate solution $(50 \mathrm{mM}, \mathrm{pH} 6.0), 100 \mu \mathrm{L} \mathrm{NADH}(3.5$ $\mathrm{mM}), \quad 50 \mu \mathrm{L}$ horse liver alcohol dehydrogenase (HLADH) (10 U) and $700 \mu \mathrm{L}$ potassium phosphate buffer $(50 \mathrm{mM}, \mathrm{pH} 6.0)$. After mixing and incubating at $30^{\circ}$ C, $50 \mu \mathrm{L}$ BFD solution was added to initiate the reaction. The descending curve was examined at $340 \mathrm{~nm}$ and the linear slope was calculated from 0 to $90 \mathrm{~s}$. The activity of the different BFD-variants was compared to the activity of the given BFD-variant under the same conditions but with $700 \mu \mathrm{L}$ potassium phosphate buffer (50 mM, pH 6.0) additionally containing $0.5 \mathrm{mM}$ thiamine diphosphate and $2.5 \mathrm{mM} \mathrm{MgSO}_{4}$. One unit is defined as the amount of enzyme that catalyses the decarboxylation of $1 \mu \mathrm{mol}$ benzoylformate per minute at $\mathrm{pH} 6.0$ and $30^{\circ} \mathrm{C}$.

\section{Results and Discussion}

Six clones of E. coli SG13009 pKK233-2, each carrying the gene for a different BFD-variant, were cultivated in $250 \mathrm{~mL}$ shake flasks containing $25 \mathrm{~mL}$ buffered LB medium with $10 \mathrm{~g} / \mathrm{L}$ glycerol. The cultures were induced with IPTG after $3 \mathrm{~h}$. Figure 1A depicts the BFD portion of total protein of the different clones during the cultivation for all applied clones. The BFD portion increases in all cases, however, the absolute level is completely different. This is astonishing, as host strain, plasmid, promoter construct and essentially the expressed gene are equivalent in all clones with only minor differences of one or two amino acids. His281Ala has the lowest portion with a value lower than $0.05 \mathrm{mg} / \mathrm{mg}$ after $30 \mathrm{~h}$, followed by the wild type with about $0.1 \mathrm{mg} / \mathrm{mg}$. The portion BFD-variants in all other clones is higher with a maximum portion of over $0.4 \mathrm{mg} / \mathrm{mg}$ for Leu 476 Pro. The volumetric carboligation activity is the value that is usually measured in a simple screening procedure. It is depicted in Figure 1B for the different BFDvariants. His281Ala has the lowest activity after $30 \mathrm{~h}$ with about $0.3 \mathrm{U} / \mathrm{mL}$, followed by the wild type with ca. $2 \mathrm{U} / \mathrm{mL}$. All other clones have higher activities, with Leu476Gln having the highest carboligation activity of 


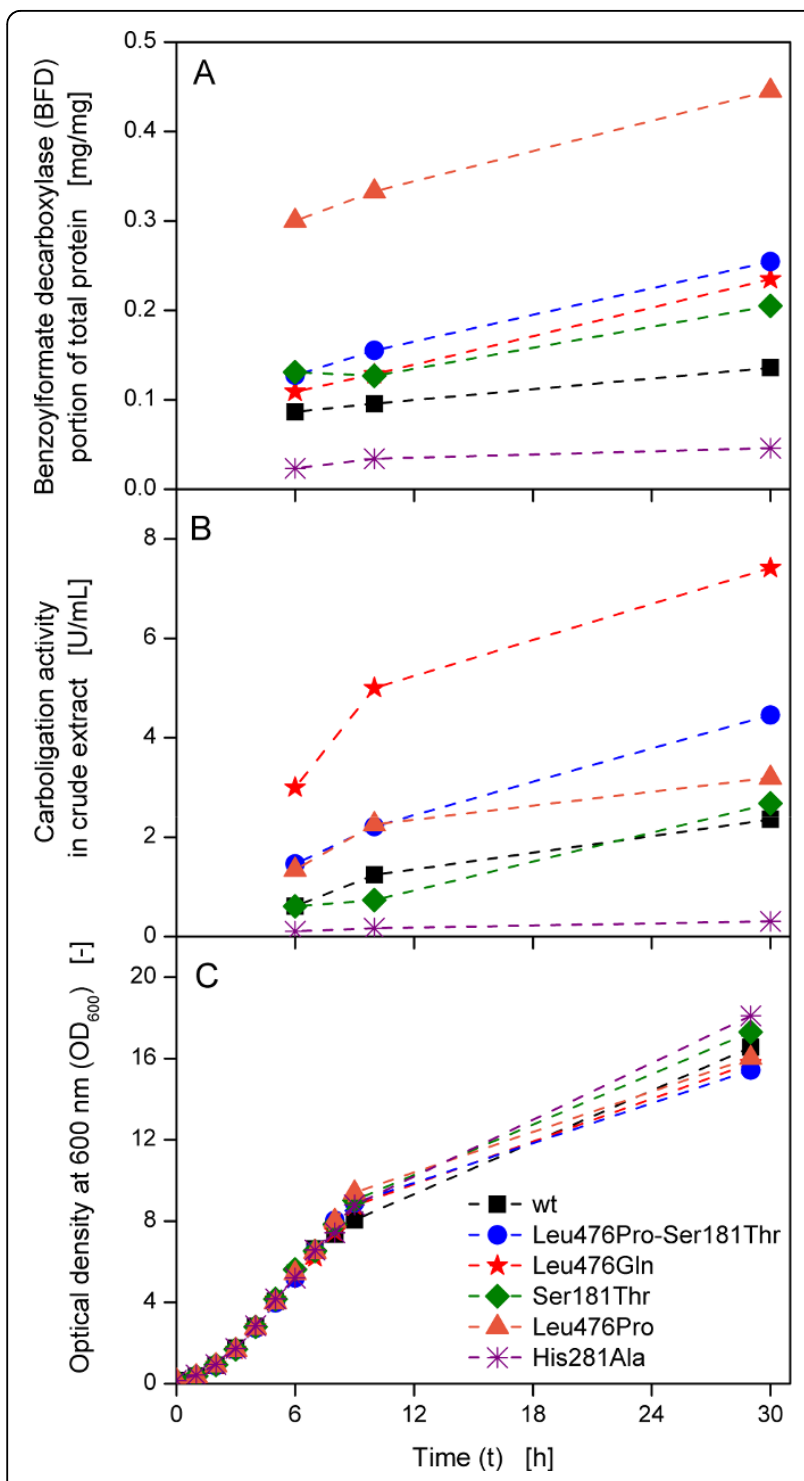

Figure 1 (A) Benzoylformate decarboxylase (BFD) portion of total protein, (B) volumetric carboligation activity in crude extract and $(C)$ optical density at $600 \mathrm{~nm}\left(\mathrm{OD}_{600}\right)$ of different BFD-variants. Buffered LB medium ( $89 \mathrm{mM}$ phosphate buffer) with $10 \mathrm{~g} / \mathrm{L}$ glycerol; IPTG induction at $3 \mathrm{~h}$; $250 \mathrm{~mL}$ shake flasks; filling volume: $25 \mathrm{~mL}$; shaking frequency: $150 \mathrm{rpm}$; shaking diameter: 50 $\mathrm{mm}$; temperature: $37^{\circ} \mathrm{C}$.

about $8 \mathrm{U} / \mathrm{mL}$. The optical densities $\left(\mathrm{OD}_{600}\right)$ of the different clones are in the same range (Figure 1C). His281Ala has the highest $\mathrm{OD}_{600}$ of about 18 after $30 \mathrm{~h}$ and Leu476Pro-Ser181Thr the lowest $\mathrm{OD}_{600}$ of about 15.5 .

Figure $2 \mathrm{~A}$ shows the corresponding OTR curves of the different $E$. coli SG13009 pKK233-2 clones cultivated in $250 \mathrm{~mL}$ RAMOS flasks containing $25 \mathrm{~mL}$ buffered LB medium with $10 \mathrm{~g} / \mathrm{L}$ glycerol. Up to about $9 \mathrm{~h}$, the curves of all clones are similar. After an exponential
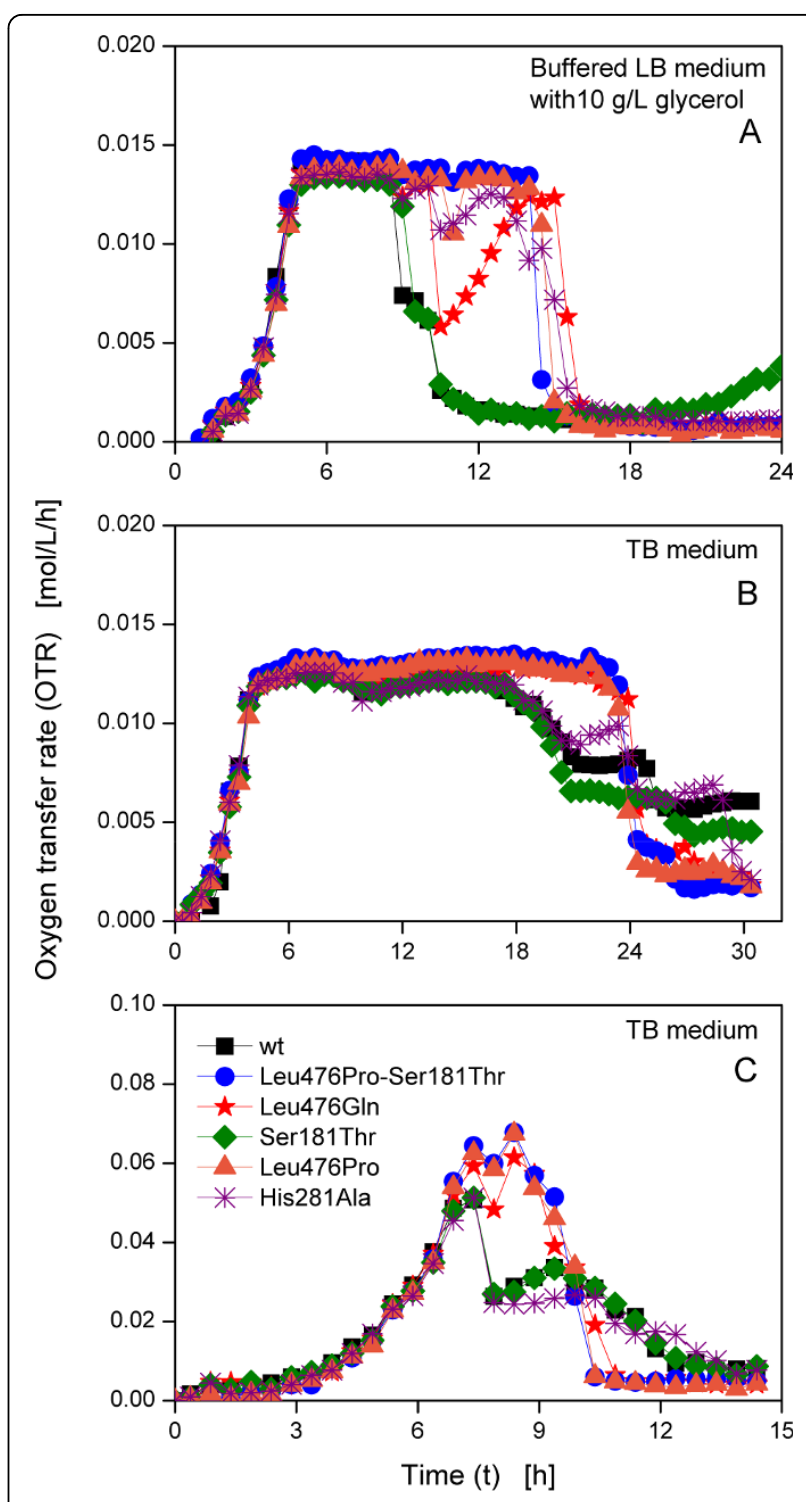

Figure 2 Oxygen transfer rates of E. coli SG13009 pKK233-2 clones producing different BFD-variants. Cultivation at $37^{\circ} \mathrm{C}$, a shaking diameter of $50 \mathrm{~mm}$ and different cultivation conditions in modified $250 \mathrm{~mL}$ shake flasks. (A) Buffered LB medium $(89 \mathrm{mM}$ phosphate buffer) with $10 \mathrm{~g} / \mathrm{L}$ glycerol; IPTG induction at $3 \mathrm{~h}$; filling volume: $25 \mathrm{~mL}$; shaking frequency: $150 \mathrm{rpm}$. (B) TB medium; IPTG induction at $3.5 \mathrm{~h}$; filling volume: $25 \mathrm{~mL}$; shaking frequency: 150 rpm. (C) TB medium; IPTG induction at $3.5 \mathrm{~h}$; filling volume: $10 \mathrm{~mL}$; shaking frequency: $400 \mathrm{rpm}$.

increase of OTR for $5 \mathrm{~h}$ to ca. $0.014 \mathrm{~mol} / \mathrm{L} / \mathrm{h}$, a plateau caused by an oxygen limitation [25] follows. A low shaking frequency in combination with a relatively high filling volume leads to an insufficient oxygen availability. Afterwards, three different types of respiration behaviours are visible. For the clones Leu476Pro-Ser181Thr and Leu476Pro, the plateau lasts up to ca. $15 \mathrm{~h}$, subsequently followed by a rapid decline, whereas the OTRs 
of the clone expressing the wild type BFD and Ser181Thr decline to $0.007 \mathrm{~mol} / \mathrm{L} / \mathrm{h}$ after only $10 \mathrm{~h}$ and reach $0.001 \mathrm{~mol} / \mathrm{L} / \mathrm{h}$ after $12 \mathrm{~h}$. The OTRs of Leu476Gln and His281Ala decline after $10 \mathrm{~h}$, too, but subsequently recover before they drop to about 0.001 $\mathrm{mol} / \mathrm{L} / \mathrm{h}$ after $16 \mathrm{~h}$ and $15 \mathrm{~h}$, respectively.

Cultivation of the E. coli SG13009 pKK233-2 clones under the same conditions in TB medium results obviously in two different types of OTR curves (Figure 2B). Again, Leu476Pro-Ser181Thr and Leu476Pro reach a plateau of $0.013 \mathrm{~mol} / \mathrm{L} / \mathrm{h}$ after an exponential increase. This plateau is again due to an oxygen limitation. Its level is slightly lower than for LB medium, as TB is a richer medium resulting in lower oxygen solubility and diffusivity [28]. After $24 \mathrm{~h}$, the OTRs drop. The OTR of the second type (wild type and Ser181Thr) also increase exponentially to $0.013 \mathrm{~mol} / \mathrm{L} / \mathrm{h}$. However, they decline already after $18 \mathrm{~h}$ to about $0.06 \mathrm{~mol} / \mathrm{L} / \mathrm{h}$. Further respiration activity at this lower level ensues before a second decline follows after ca. $25 \mathrm{~h}$. In contrast to the first cultivation shown in Figure 2A, here, Leu476Gln and His281Ala behave like the first type and the second type, respectively.

To surely avoid an oxygen limitation, another experiment with a lower filling volume $(10 \mathrm{~mL})$ and higher shaking frequency $(400 \mathrm{rpm})$ was conducted (Figure $2 \mathrm{C}$ ). No plateau of the OTR was observed. Again, different types of OTR curves depending on the clones occurred. Up to about $7 \mathrm{~h}$, all OTRs increase exponentially to $0.065 \mathrm{~mol} / \mathrm{L} / \mathrm{h}$, yet the following respiration behaviours differ. The OTRs of the first type (Leu476Pro-Ser181Thr, Leu476Gln and Leu476Pro) slightly drop, before another increase until ca. $8.5 \mathrm{~h}$ follows. All three curves drop after $11 \mathrm{~h}$. The curves of the second type (the clone expressing the wild type BFD, Ser181Thr and His281Ala), however, drop to ca. $0.025 \mathrm{~mol} / \mathrm{L} / \mathrm{h}$ after $8 \mathrm{~h}$. The OTR of His281Ala remains at this level, while the curves of the clone expressing the wild type BFD and Ser181Thr recover to over $0.03 \mathrm{~mol} / \mathrm{L} / \mathrm{h}$ after 9.5 h. Subsequently, all three curves decline steadily.

From Figure $2 \mathrm{~A}-\mathrm{C}$, three different groups of clones can be distinguished on basis of the OTR curves. The first group consists of Leu476Pro-Ser181Thr and Leu476Pro, which show typical OTR curves under oxygen limited and not oxygen limited conditions. In contrast, the OTR of the second type shows an earlier drop of OTR which is followed by further respiration activity on a lower level in TB medium. The third type (Leu476Gln and His281Ala) shows a variable behaviour, depending on the cultivation conditions. All these clones, having only very small differences in their genetic construction, behave surprisingly different in their metabolic activity, proving the differences that were already found in their expression properties shown in Figure 1.
As the applied E. coli strain SG13009 is thiamine auxotroph and thiamine is needed for growth as well as a cofactor for BFD, it was supposed that thiamine caused this astonishing behaviour. However, it must be stressed that LB and TB media are usually applied without any supplementation of additional thiamine [21-23]. Thus, further cultivations were conducted in normal TB medium with additional thiamine supplementation. To test one clone of each type, Leu476Pro and the clone expressing the wild type BFD were chosen. While the first exhibited no early drop of respiration activity under all investigated culture conditions, the latter showed an early drop of respiration activity. Both clones were cultivated in TB medium with and without $0.1 \mathrm{mg} / \mathrm{L}$ additional thiamine. The Leu476Pro clone was induced after $3.5 \mathrm{~h}$, resulting in OTR curves that are nearly identical, irrespective of thiamine addition (Figure 3A). The same cultivations were conducted with the clone expressing the wild type BFD, yet one culture in each medium was induced after $3.5 \mathrm{~h}$ and one was not induced. Figure 3B

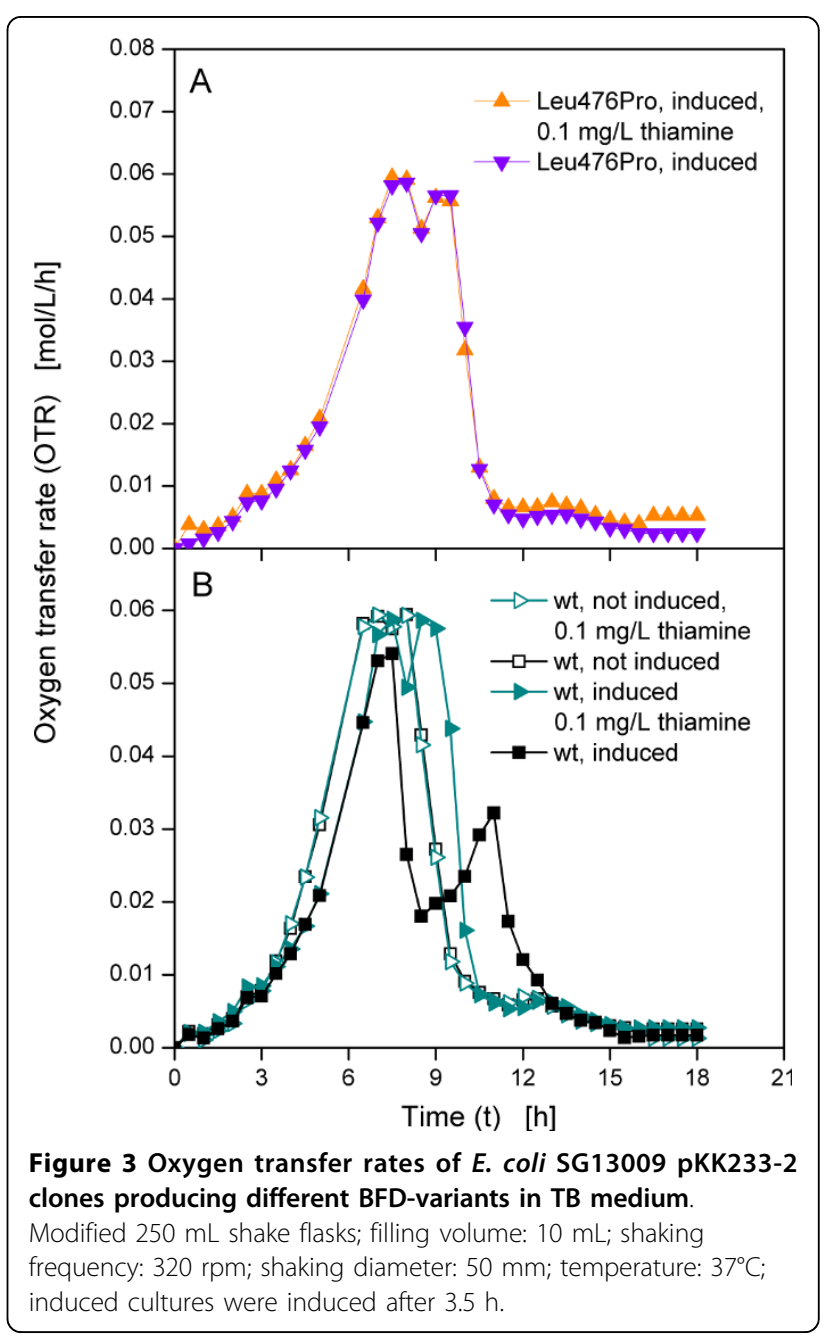


shows the OTRs of these cultures. Compared to the non-induced cultures, the induced cultures show a slower increase of OTR upon induction after $3.5 \mathrm{~h}$ due to the metabolic burden, the cultures are exposed to. That means, cellular resources are used for the production of BFD, thus reducing the growth of the cultures $[29,30]$. The curves of the non-induced cultures are nearly identical in both media, whereas the curves of the induced cultures differ. The OTR of the induced clone that expresses the wild type BFD in TB medium rises to about $0.05 \mathrm{~mol} / \mathrm{L} / \mathrm{h}$ after $8 \mathrm{~h}$, drops to below $0.02 \mathrm{~mol} / \mathrm{L} / \mathrm{h}$ after $9 \mathrm{~h}$ and increases to $0.03 \mathrm{~mol} / \mathrm{L} / \mathrm{h}$ after $11 \mathrm{~h}$, before it declines to nearly $0 \mathrm{~mol} / \mathrm{L} / \mathrm{h}$ after about $15 \mathrm{~h}$. Up to $8 \mathrm{~h}$ the curve of the induced culture in TB medium with additional thiamine is similar, yet the following decline is smaller. The OTR only decreases to about $0.05 \mathrm{~mol} / \mathrm{L} / \mathrm{h}$, before it rises again to approximately $0.06 \mathrm{~mol} / \mathrm{L} / \mathrm{h}$ after $9 \mathrm{~h}$.

The addition of thiamine seems to have no effect on the growth of Leu476Pro. This clone shows no limitation in TB medium without additional thiamine and the OTR curves of Leu476Pro in TB medium with and without additional thiamine hardly differ. For the induced clone expressing the wild type BFD, the addition of thiamine to the medium leads to an OTR curve without early decrease. Apart from a slower increase due to the metabolic burden, the curve of the induced culture with additional thiamine is similar to the curves of the non-induced cultures. These results support the assumption that the early drop of OTR during the cultivation of the clone expressing the wild type BFD in TB medium without additional thiamine was caused by the level of thiamine concentration.

In complex medium thiamine is part of the complex compounds. Thiamine is heat sensitive, and, thus, might partially be degraded when the medium is autoclaved. Therefore, variances in the duration of autoclaving and the subsequent cooling may cause different thiamine concentrations in the medium. Additionally, the amount of thiamine in the complex compounds can vary, too, leading to an undefined thiamine concentration in the medium. A mineral medium was, thus, applied for further cultivations. To determine the required amount of glycerol and thiamine, the clone expressing the wild type BFD was cultivated in modified PanG mineral medium with different glycerol and thiamine concentrations. To avoid the problem of heat degradation of thiamine, sterile filtrated thiamine solution was added after the medium was autoclaved. Figure $4 \mathrm{~A}$ shows the OTR curves of the clone expressing the wild type BFD in PanG medium with $10 \mathrm{mg} / \mathrm{L}$ thiamine and different glycerol concentration. The cultures in PanG medium with $8 \mathrm{~g} / \mathrm{L}$ and $10 \mathrm{~g} / \mathrm{L}$ glycerol are nearly identical and show OTR curves typical for batch cultures, with the culture

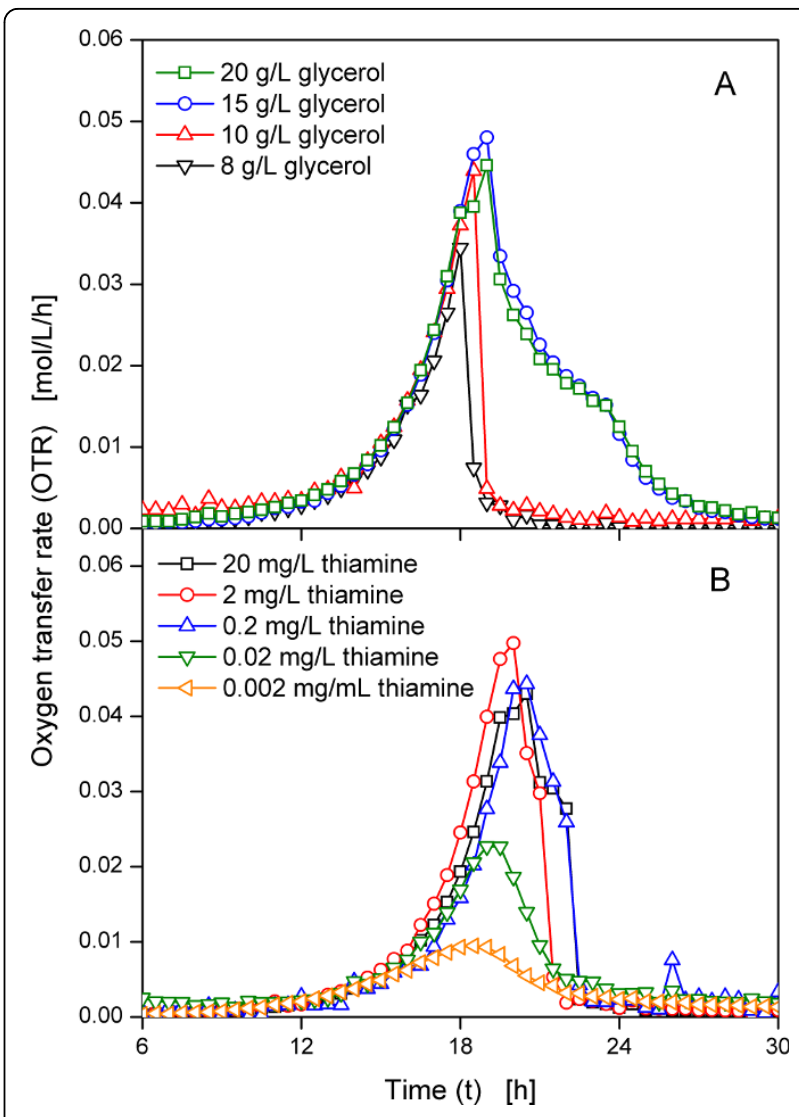

Figure 4 Oxygen transfer rates of $E$. coli SG13009 pKK233-2 expressing wild type BFD in modified PanG mineral medium.

Modified $250 \mathrm{~mL}$ shake flasks; filling volume: $10 \mathrm{~mL}$; shaking frequency: $320 \mathrm{rpm}$; shaking diameter: $50 \mathrm{~mm}$; temperature: $37^{\circ} \mathrm{C}$; all OTRs are shown from $6 \mathrm{~h}$ to enlarge the relevant part of the graphs. (A) Different initial glycerol concentration $(10 \mathrm{mg} / \mathrm{L}$ thiamine). (B) Different initial thiamine concentration (10 g/L glycerol).

in medium with $10 \mathrm{~g} / \mathrm{L}$ glycerol having a higher maximum OTR of $0.045 \mathrm{~mol} / \mathrm{L} / \mathrm{h}$. Whereas the first part of the OTR curves of the cultures with $20 \mathrm{~g} / \mathrm{L}$ and $15 \mathrm{~g} / \mathrm{L}$ glycerol is also identical up to about $20 \mathrm{~h}$, the subsequent slow decline suggests another limitation [25], which was, however, not further investigated in this work. As this limitation does not occur in PanG medium with $10 \mathrm{~g} / \mathrm{L}$ glycerol, this concentration was applied for further cultivations.

The thiamine concentration was varied between 0.002 $\mathrm{mg} / \mathrm{L}$ and $20 \mathrm{mg} / \mathrm{L}$ (Figure $4 \mathrm{~B}$ ). The highest maximum OTR of $0.05 \mathrm{~mol} / \mathrm{L} / \mathrm{h}$ is obtained by the culture with 2 $\mathrm{mg} / \mathrm{L}$ thiamine. Up to this concentration, increasing the thiamine concentration results in an increased maximum OTR. However, the addition of $20 \mathrm{mg} / \mathrm{L}$ thiamine leads to a lower maximum OTR of about $0.04 \mathrm{~mol} / \mathrm{L} / \mathrm{h}$. While a concentration of $0.02 \mathrm{mg} / \mathrm{L}$ thiamine is sufficient to allow the growth of the applied clone, a 
concentration of $0.05 \mathrm{mg} / \mathrm{L}$ thiamine was selected for further cultivations to ensure a sufficient thiamine concentration during further cultivations with induction.

Five E. coli SG13009 pKK233-2 clones expressing different BFD-variants (Leu476Pro-Ser181Thr, wild type, Leu476His, Leu476Gln and Ser181Thr) were selected for cultivation in modified PanG mineral medium with $10 \mathrm{~g} / \mathrm{L}$ glycerol and $0.05 \mathrm{mg} / \mathrm{L}$ thiamine. As mentioned before, Figure 2 indicates three different types of clones. Thus, Leu476Pro-Ser181Thr was selected as an example for the first type which exhibited a sharp drop of OTR after a relative long time. The clone expressing the wild type BFD and Ser181Thr belong to the second type with an earlier drop of OTR and a subsequent growth at a lower OTR. For the third type, which shows variable OTR depending on the cultivation conditions, Leu476Gln was chosen. One culture of each clone was induced after $16 \mathrm{~h}$ with IPTG and one was not induced. Figure 5A depicts the OTR curves of the clone expressing the wild type BFD and Leu476Pro-Ser181Thr. Without induction, the OTR curves of the clone expressing the wild type BFD and Leu476Pro-Ser181Thr have the same shape (Figure 5A). After reaching a maximum OTR of about $0.04 \mathrm{~mol} / \mathrm{L} / \mathrm{h}$ after $18 \mathrm{~h}$ the OTR drops to $0.005 \mathrm{~mol} / \mathrm{L} / \mathrm{h}$ after $21 \mathrm{~h}$. In contrast, the OTR curves of the induced cultures differ. Upon induction after 16 $\mathrm{h}$, the slope of the curves of Leu476Pro-Ser181Thr decreases in comparison to the not induced culture, probably explained by the metabolic burden. It reaches its maximum OTR of about $0.025 \mathrm{~mol} / \mathrm{L} / \mathrm{h}$ after $21 \mathrm{~h}$. The curve of the clone expressing the wild type BFD, however, reaches a maximum OTR of only $0.01 \mathrm{~mol} / \mathrm{L} /$ $\mathrm{h}$ after $18 \mathrm{~h}$, followed by a decline to about $0.002 \mathrm{~mol} /$ $\mathrm{L} / \mathrm{h}$ after $24 \mathrm{~h}$.

The OTR curves of the clones expressing Leu476His, Leu476Gln and Ser181Thr without induction are also similar (Figure $5 \mathrm{~B}$ ). They show a maximum OTR of about $0.04 \mathrm{~mol} / \mathrm{L} / \mathrm{h}$ after ca. $18 \mathrm{~h}$. For Leu476His, the OTR of the induced culture does not change in comparison to the not induced culture, but has a reduced maximum OTR of $0.03 \mathrm{~mol} / \mathrm{L} / \mathrm{h}$ and a decreased slope upon induction, which is again caused by the metabolic burden. For the clones Ser181Thr and Leu476Gln, however, the curves of the induced cultures vary strongly compared to the curves of the not induced cultures. With a maximum OTR of $0.01 \mathrm{~mol} / \mathrm{L} / \mathrm{h}$, the OTR of the induced Ser181Thr culture is similar to the OTR of the clone expressing the wild type BFD shown in Figure 5A. After induction at $16 \mathrm{~h}$, the OTR of Leu476Gln increases slowly to $0.015 \mathrm{~mol} / \mathrm{L} / \mathrm{h}$ after $24 \mathrm{~h}$.

Regarding the induced cultures in Figure $5 \mathrm{~A}$ and $5 \mathrm{~B}$, three different types of OTR curves can be distinguished. The first type (Leu476Pro-Ser181Thr and Leu476His) has a similar respiration activity as the non-

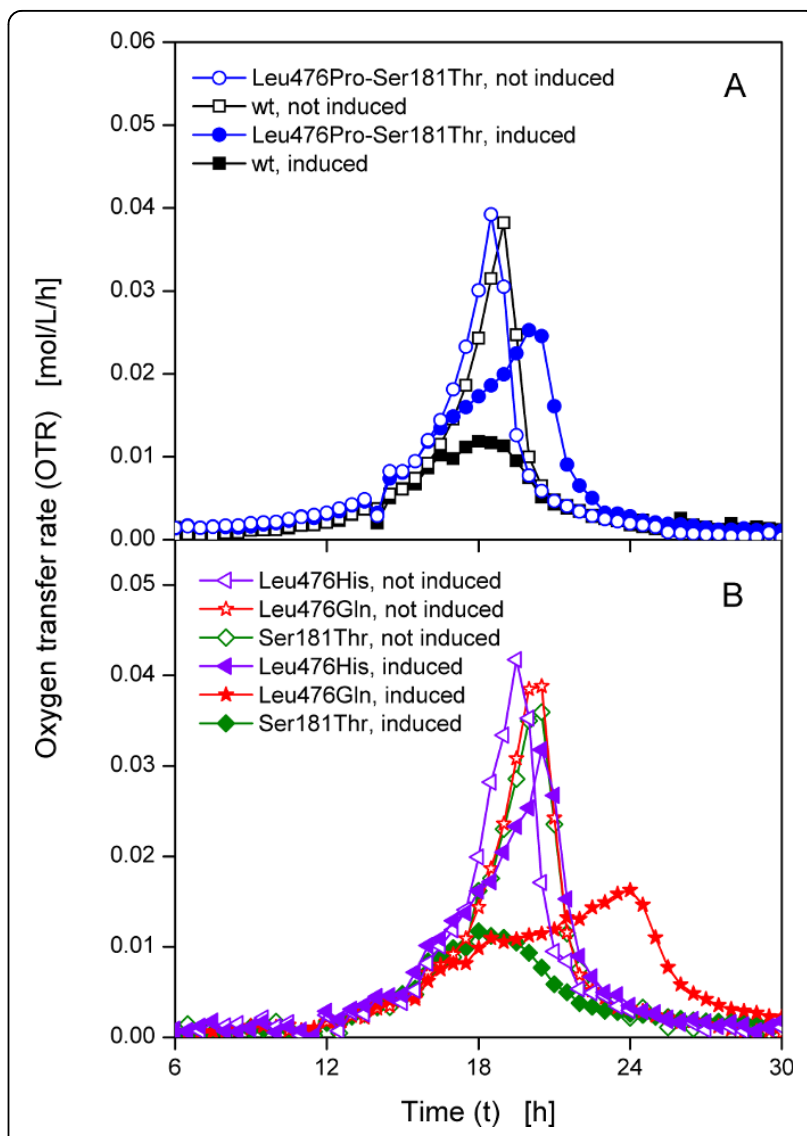

Figure 5 Oxygen transfer rates of clones of E. coli SG13009 pKK233-2 expressing different BFD-variants in modified PanG mineral medium with $\mathbf{0 . 0 5} \mathbf{~} \mathbf{g} / \mathbf{L}$ thiamine. (A) wild type and Leu476Pro-Ser181Thr. (B) Leu476His, Leu476GIn and Ser181Thr. Modified $250 \mathrm{~mL}$ shake flasks; filling volume: $10 \mathrm{~mL}$; shaking frequency: $320 \mathrm{rpm}$; shaking diameter: $50 \mathrm{~mm}$; temperature: $37^{\circ} \mathrm{C}$ induced cultures were induced after 16 h; all OTR are shown from 6 $h$ to enlarge the relevant part of the graphs.

induced cultures with a slightly reduced maximum OTR and a reduced initial increase of OTR upon induction due to the metabolic burden. In contrast to the OTR in complex medium (Figure $2 \mathrm{C}$ and $3 \mathrm{~B}$ ), the OTR of the second type (the clone expressing the wild type BFD and Ser181Thr) in mineral medium does not drop after a certain time, but shows a strongly decreased maximum OTR. Upon induction, the slope of the OTR curve of the third type (Leu476Gln) is drastically reduced, resulting in a maximum OTR of only $0.02 \mathrm{~mol} / \mathrm{L} / \mathrm{h}$ after $24 \mathrm{~h}$.

Figure 6 shows the residual enzyme activity of the

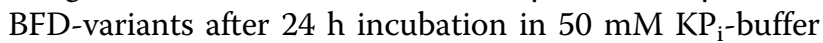
without thiamine. The BFD-variants His281Ala, Ser181Thr and the wild type BFD have about $100 \%$ residual enzyme activity after $24 \mathrm{~h}$, whereas no activity is detected for Leu476His, Leu476Pro and Leu476ProSer181Thr. In contrast, Leu476Gln neither maintains 


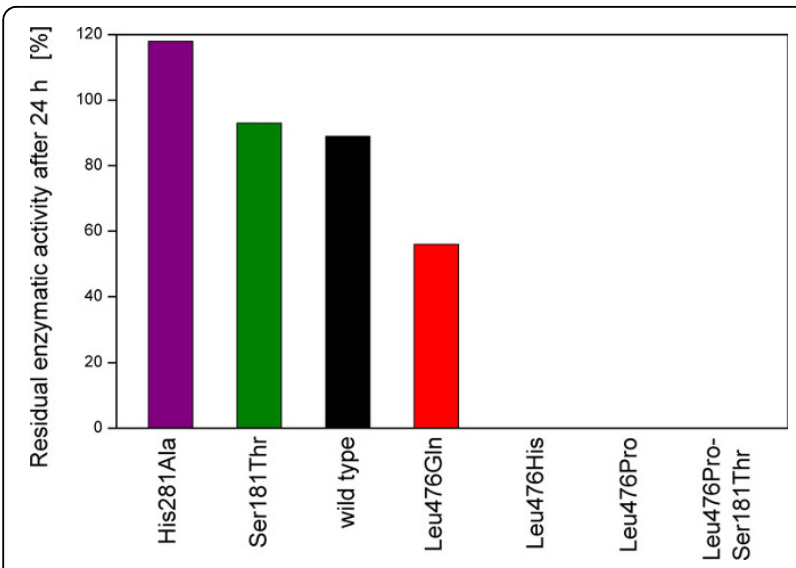

Figure 6 Residual enzyme activity of different BFD-variants

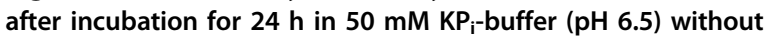
thiamine. The residual enzyme activity of the given variant refers to its activity in $50 \mathrm{mM} \mathrm{KP} \mathrm{i}_{\mathrm{i}}$-buffer ( $\mathrm{pH}$ 6.5) with thiamine (according to Lingen et al. [4])

$100 \%$ of its enzyme activity after $24 \mathrm{~h}$, nor looses it completely. After $24 \mathrm{~h}$ incubation, it retains a residual enzyme activity of about $60 \%$. The reason for these differences in residual enzymatic activity might be the different cofactor binding strength of the variants. A high residual enzyme activity implies that the cofactor thiamine was not washed out because of the high cofactor binding strength of the given BFD-variants, whereas a low residual enzyme activity is caused by a low cofactor binding strength. After $24 \mathrm{~h}$ incubating in cofactor free buffer the cofactor, thiamine dissociated from Leu476His, Leu476Pro and Leu476Pro-Ser181Thr, therefore disabling their enzymatic activity.

According to Lingen et al. [4], Leu476 is located near, but not in the active centre of the enzyme and is involved in contacts between two of the four monomers the enzyme consists of [31]. The authors suppose it to have an influence on the cofactor binding strength, thus, by exchanging the amino acid at this position the cofactor binding strength of the enzyme can be altered. While the exchange of leucine by histidine or proline leads to a lower cofactor binding strength, exchanging it for glutamine also reduces the cofactor binding strength, but to a lesser degree. Contrarily, the replacement at the positions 181 and 281 does not reduce the cofactor binding strength.

These different cofactor binding strengths might explain the different OTR curves of the clones. Thiamine is a cofactor of BFD as well as of enzymes of the central carbon metabolism of $E$. coli, such as the pyruvate dehydrogenase complex (PDHc) [32]. The PDHc catalyses the formation of $\mathrm{CO}_{2}$, Acetyl-CoA (which is further utilised in the citric acid cycle) and $\mathrm{NADH}_{2}{ }^{+}$ (which is used in the electron transport chain), from pyruvate, coenzyme A and $\mathrm{NAD}^{+}$[33]. Here, thiamine pyrophosphate (ThDP) is a cofactor of the subunit pyruvate dehydrogenase that deacetylates pyruvate under $\mathrm{CO}_{2}$-formation. ThDP is supposed to actively participate in the reaction of pyruvate dehydrogenase [34-37]. Thus, if thiamine is bound by other enzymes such as BFD and, in consequence, is not available for the PDHc, the reaction of the PDHc might be hampered, resulting in different OTR curves.

Besides its role as cofactor for several enzymes, thiamine in its phosphorylated form ThDP is also involved in the regulation of genes of the thiamine biosynthesis. In E. coli, the operons thiCEFSGH, thiMD and tbpAthiPQ, which code for enzymes of the thiamine biosynthesis and thiamine transporters, are regulated by ThDP [38]. ThDP binds at a conserved, untranslated RNA structure that is called thi box without involvement of protein cofactors. When thiamine is bound at this thi box riboswitch, the structure of the mRNA changes, masking the Shine-Dalgarno box and, thus, hindering the initiation of translation [39]. In consequence, the gene expression of the thi box riboswitch regulated genes is reduced [40] if thiamine is present in the medium, whereas in case of a lack of thiamine, the Shine-Dalgarno box is not masked and the gene expression is, thus, not hampered.

\section{Conclusions}

This study showed that even a slight alteration of the amino acid composition of BFD has a surprisingly large effect on the expression and the metabolic activity of the applied host strain. The E. coli SG13009 pKK233-2 clones, each harbouring the gene for a different BFDvariant, not only express different amounts of the respective BFD-variant, but also show strongly varying OTR curves during cultivation. It was shown that the OTR curves of the clones are dependent on the thiamine availability in the medium which, in turn, is supposed to be dependent on the cofactor affinity of the expressed BFD-variants. Because thiamine is not only a cofactor for BFD, but also for other enzymes that are involved in the metabolism of $E$. coli, the different cofactor binding strengths and, thus, the availability of thiamine in the medium might be an explanation for the differences in the OTR curves. Leu476His, Leu476Pro and Leu476Pro-Ser181Thr are BFD-variants with low cofactor binding strength. As only a fraction of thiamine is bound by the BFD-variants, the medium contains enough thiamine to enable normal growth of these clones (Figure 7A). In contrast, the higher cofactor affinity of the wild type, His281Ala, Ser181Thr and partially Leu476Gln leads to impaired respiration and growth of the clones producing these BFD-variants, as the thiamine is presumably extracted from the medium and 


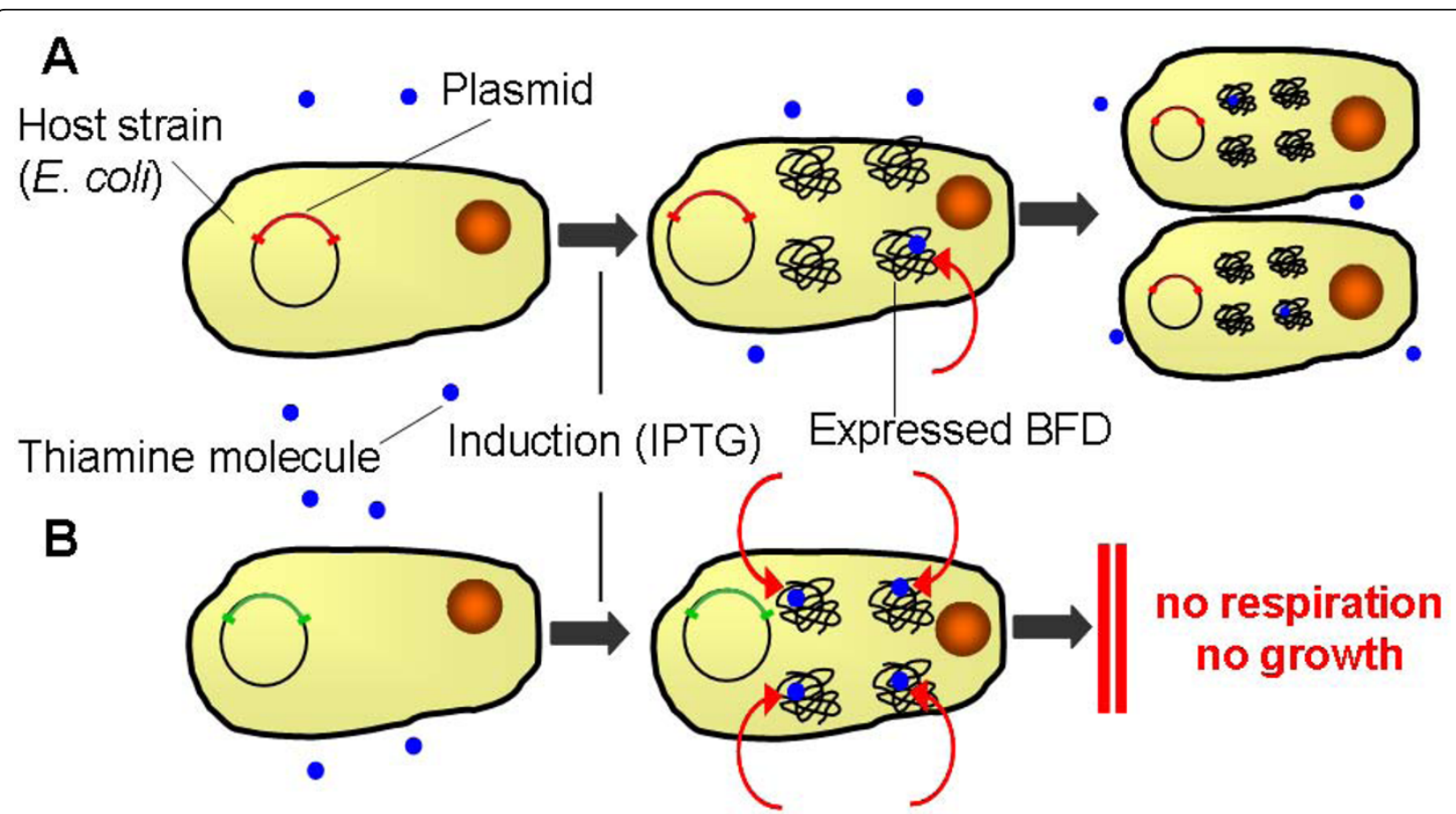

Figure 7 Mechanistic reason for the behaviour of $E$. coli SG13009 pKK233-2 clones expressing different BFD-variants. (A) BFD-variants with high cofactor binding strength: wild type, His281Ala, Ser181Thr, and partially Leu476Gln. As the thiamine is bound by these BFD-variants with high binding strength, it is not available in the medium and, thus, the growth of these strains is impaired. (B) BFD-variants with low cofactor binding strength: Leu476His, Leu476Pro, Leu476Pro-Ser181Thr.

bound by the BFD-variants and is, hence, not available for growth (Figure 7B). The intermediate cofactor binding strength of Leu476Gln is a likely explanation for the OTR curves of this clone. Although it binds thiamine, the thiamine still can partially be dissociated, leading to variable respiration behaviour, depending on the cultivation conditions. Whereas this clone behaves like the first type in TB medium (Figure 2B and 2C), its OTR in modified PanG mineral medium is more similar to the second type. Its medium cofactor binding strength allows growth at a slower rate and a reduced maximum OTR compared to the first type, but for a longer time than the second type (Figure $5 \mathrm{~B}$ ).

As shown in this study, addition of thiamine to the medium can prevent the observed differing growth kinetics and is, thus, strongly recommended. While thiamine was identified as the cause for the differing growth kinetics in these experiments, other cultivations might be influenced by different effects. Unexpected phenomena such as the observed are hardly detectable in conventional screening processes. This might lead to wrong selection of enzyme variants, wrong assumptions about the optimal point of harvest and, ultimately, to wasted resources. To realise such hardly foreseeable effects influencing cultivation and expression of products, the application of on-line monitoring systems is, therefore, advised in screening processes.

While this study was conducted with the thiamine auxotroph strain E. coli SG13009, further studies should focus on prototrophic strains, such as E. coli BL21, to investigate, if the different binding strengths of the BFD-variants effect the OTR of these strains, too.

\section{Author details}

'AVT - Aachener Verfahrenstechnik, Biochemical Engineering, RWTH Aachen University, Worringerweg 1, D-52074 Aachen, Germany. ${ }^{2}$ Institute of Molecular Enzyme Technology, Heinrich-Heine University Düsseldorf, Research Centre Jülich, D-52426 Jülich, Germany. ${ }^{3}$ Bioprocess R\&D, Dow AgroSciences LLC, Indianapolis, USA. ${ }^{4}$ Current Address: Institute of Biotechnology 2, Forschungszentrum Jülich GmbH, D-52425 Jülich, Germany.

\section{Authors' contributions}

TGP prepared the manuscript. JN performed the cultivation experiments. BF provided the applied strains and determined the cofactor binding strength of the different BFD-variants. MP planned the His281Ala variant and conducted structure-function studies of all variants on the basis of their 3Dstructure. WT sponsored the project and assisted in the interpretation of the results. JB initiated the project, assisted with data analysis and manuscript preparation. All authors read and approved the final manuscript.

\section{Competing interests}

The authors declare that they have no competing interests.

Received: 5 July 2010 Accepted: 19 October 2010 Published: 19 October 2010 


\section{References}

1. Short JM: Recombinant approaches for accessing biodiversity. Nat Biotechnol 1997, 15(13):1322-1323.

2. Stemmer WP: DNA shuffling by random fragmentation and reassembly: in vitro recombination for molecular evolution. Proc Natl Acad Sci USA 1994, 91(22):10747-10751.

3. Dünnwald T, Demir AS, Siegert P, Pohl M, Muller M: Enantioselective synthesis of (S)-2-hydroxypropanone derivatives by benzoylformate decarboxylase catalyzed C-C bond formation. European Journal of Organic Chemistry 2000, 11: 2161-2170

4. Lingen B, Grotzinger J, Kolter D, Kula MR, Pohl M: Improving the carboligase activity of benzoylformate decarboxylase from Pseudomonas putida by a combination of directed evolution and sitedirected mutagenesis. Protein Eng 2002, 15(7):585-593.

5. Lingen B, Kolter-Jung D, Dunkelmann P, Feldmann R, Grotzinger J, Pohl M Muller M: Alteration of the substrate specificity of benzoylformate decarboxylase from Pseudomonas putida by directed evolution. Chembiochem 2003, 4(8):721-726.

6. Pohl M, Siegert P, Mesch K, Bruhn H, Grotzinger J: Active site mutants of pyruvate decarboxylase from Zymomonas mobilis-a site-directed mutagenesis study of L112, 1472, 1476, E473, and N482. Eur J Biochem 1998, 257(3):538-546.

7. Gunsalus CF, Stanier RY, Gunsalus IC: The enzymatic conversion of mandelic acid to benzoic acid. III. Fractionation and properties of the soluble enzymes. J Bacteriol 1953, 66(5):548-553.

8. Gunsalus IC, Gunsalus CF, Stanier RY: The enzymatic conversion of mandelic acid to benzoic acid. I. Gross fractionation of the system into soluble and particulate components. J Bacteriol 1953, 66(5):538-542.

9. Stanier RY, Gunsalus IC, Gunsalus CF: The enzymatic conversion of mandelic acid to benzoic acid. II. Properties of the particulate fractions. $J$ Bacteriol 1953, 66(5):543-547

10. Wilcocks R, Ward OP, Collins S, Dewdney NJ, Hong Y, Prosen E: Acyloin formation by benzoylformate decarboxylase from Pseudomonas putida. Appl Environ Microbiol 1992, 58(5):1699-1704.

11. Iding H, Dunnwald T, Greiner L, Liese A, Muller M, Siegert P, Grotzinger J, Demir AS, Pohl M: Benzoylformate decarboxylase from Pseudomonas putida as stable catalyst for the synthesis of chiral 2-hydroxy ketones. Chemistry 2000, 6(8):1483-1495.

12. Drepper T, Eggert T, Hummel W, Leggewie C, Pohl M, Rosenau F, Jaeger KE: New biocatalysts for White Biotechnology. Chemie Ingenieur Technik 2006, 78(3):239-248

13. Siegert $P$, McLeish MJ, Baumann M, Iding $H$, Kneen MM, Kenyon GL, Pohl M: Exchanging the substrate specificities of pyruvate decarboxylase from Zymomonas mobilis and benzoylformate decarboxylase from Pseudomonas putida. Protein Eng Des Sel 2005, 18(7):345-357.

14. Gocke D, Walter L, Gauchenova E, Kolter G, Knoll M, Berthold CL, Schneider G, Pleiss J, Muller M, Pohl M: Rational protein design of ThDPdependent enzymes-engineering stereoselectivity. Chembiochem 2008 9(3):406-412.

15. Kensy F, Engelbrecht C, Büchs J: Scale-up from microtiter plate to laboratory fermenter: evaluation by online monitoring techniques of growth and protein expression in Escherichia coli and Hansenula polymorpha fermentations. Microb Cell Fact 2009, 8:68

16. Asztalos P, Parthier C, Golbik R, Kleinschmidt M, Hubner G, Weiss MS, Friedemann R, Wille G, Tittmann K: Strain and near attack conformers in enzymic thiamin catalysis: X-ray crystallographic snapshots of bacterial transketolase in covalent complex with donor Ketoses xylulose 5 phosphate and fructose 6-phosphate, and in noncovalent complex with acceptor aldose ribose 5-phosphate. Biochemistry 2007, 46(43):12037-12052.

17. Fang R, Nixon PF, Duggleby RG: Identification of the catalytic glutamate in the E1 component of human pyruvate dehydrogenase. Febs Letters 1998, 437(3):273-277.

18. Huang CY, Chang AK, Nixon PF, Duggleby RG: Site-directed mutagenesis of the ionizable groups in the active site of Zymomonas mobilis pyruvate decarboxylase - Effect on activity and $\mathrm{pH}$ dependence. European Journal of Biochemistry 2001, 268(12):3558-3565.

19. Schenk G, Leeper FJ, England R, Nixon PF, Duggleby RG: The role of His113 and His114 in pyruvate decarboxylase from Zymomonas mobilis. European Journal of Biochemistry 1997, 248(1):63-71.
20. Pan JG, Rhee JS, Lebeault JM: Physiological constraints in increasing biomass concentration of Escherichia coli B in fed-batch cultures. Biotechnology Letters 1987, 9(2):89-94.

21. Frey KM, Oppermann-Sanio FB, Schmidt H, Steinbuchel A: Technical-scale production of cyanophycin with recombinant strains of Escherichia coli. Appl Environ Microbiol 2002, 68(7):3377-3384.

22. Koschorreck K, Schmid RD, Urlacher VB: Improving the functional expression of a Bacillus licheniformis laccase by random and sitedirected mutagenesis. BMC Biotechnol 2009, 9:12.

23. Yoshimoto T, Murayama N, Honda T, Tone H, Tsuru D: Cloning and expression of aminopeptidase $\mathrm{P}$ gene from Escherichia coli HB101 and characterization of expressed enzyme. J Biochem 1988, 104(1):93-97.

24. Anderlei $T$, Zang $W$, Papaspyrou M, Büchs J: Online respiration activity measurement (OTR, CTR, RQ) in shake flasks. Biochemical Engineering Journal 2004, 17(3):187-194.

25. Anderlei T, Büchs J: Device for sterile online measurement of the oxygen transfer rate in shaking flasks. Biochem Eng J 2001, 7(2):157-162.

26. Losen M, Frolich B, Pohl M, Büchs J: Effect of oxygen limitation and medium composition on Escherichia coli fermentation in shake-flask cultures. Biotechnol Prog 2004, 20(4):1062-1068.

27. Bradford MM: A rapid and sensitive method for the quantitation of microgram quantities of protein utilizing the principle of protein-dye binding. Anal Biochem 1976, 72:248-254.

28. Maier $U$, Büchs J: Characterisation of the gas-liquid mass transfer in shaking bioreactors. Biochem Eng J 2001, 7(2):99-106.

29. Glick BR: Metabolic load and heterologous gene expression. Biotechnol Adv 1995, 13(2):247-261.

30. Bonomo J, Gill RT: Amino acid content of recombinant proteins influences the metabolic burden response. Biotechnol Bioeng 2005, 90(1):116-126.

31. Hasson MS, Muscate A, McLeish MJ, Polovnikova LS, Gerlt JA, Kenyon GL, Petsko GA, Ringe D: The crystal structure of benzoylformate decarboxylase at 1.6 A resolution: diversity of catalytic residues in thiamin diphosphate-dependent enzymes. Biochemistry 1998, 37(28):9918-9930.

32. Koike $M$, Reed $\amalg$, Carroll WR: alpha-Keto acid dehydrogenation complexes. I. Purification and properties of pyruvate and alphaketoglutarate dehydrogenation complexes of Escherichia coli. J Biol Chem 1960, 235:1924-1930

33. Reed LJ: Multienzyme Complexes. Accounts of Chemical Research 1974, 7(2):40-46.

34. Jordan F: Current mechanistic understanding of thiamin diphosphatedependent enzymatic reactions. Nat Prod Rep 2003, 20(2):184-201.

35. Jordan F, Mariam YH: N1'-Methylthiaminium Diiodide - Model Study on Effect of a Coenzyme Bound Positive Charge on Reaction-Mechanisms Requiring Thiamin Pyrophosphate. Journal of the American Chemical Society 1978, 100(8):2534-2541.

36. Nemeria N, Chakraborty S, Baykal A, Korotchkina LG, Patel MS, Jordan F: The 1 ', '-iminopyrimidine tautomer of thiamin diphosphate is poised for catalysis in asymmetric active centers on enzymes. Proceedings of the National Academy of Sciences of the United States of America 2007 104(1):78-82

37. Schellenberger A: Sixty years of thiamin diphosphate biochemistry. Biochimica Et Biophysica Acta-Protein Structure and Molecular Enzymology 1998, 1385(2):177-186.

38. Jurgenson CT, Begley TP, Ealick SE: The Structural and Biochemical Foundations of Thiamin Biosynthesis. Annual Review of Biochemistry 2009, 78:569-603.

39. Miranda-Rios J, Navarro M, Soberon M: A conserved RNA structure (thi box) is involved in regulation of thiamin biosynthetic gene expression in bacteria. Proceedings of the National Academy of Sciences of the United States of America 2001, 98(17):9736-9741.

40. Winkler W, Nahvi A, Breaker RR: Thiamine derivatives bind messenger RNAs directly to regulate bacterial gene expression. Nature 2002, 419(6910):952-956.

doi:10.1186/1475-2859-9-76

Cite this article as: Palmen et al:: Physiological relation between respiration activity and heterologous expression of selected benzoylformate decarboxylase variants in Escherichia coli. Microbial Cell Factories 2010 9:76. 